\title{
STIFFNESS CONTROL OF ORTHOPAEDIC MATTRESS
}

\author{
Radek Votrubec
}
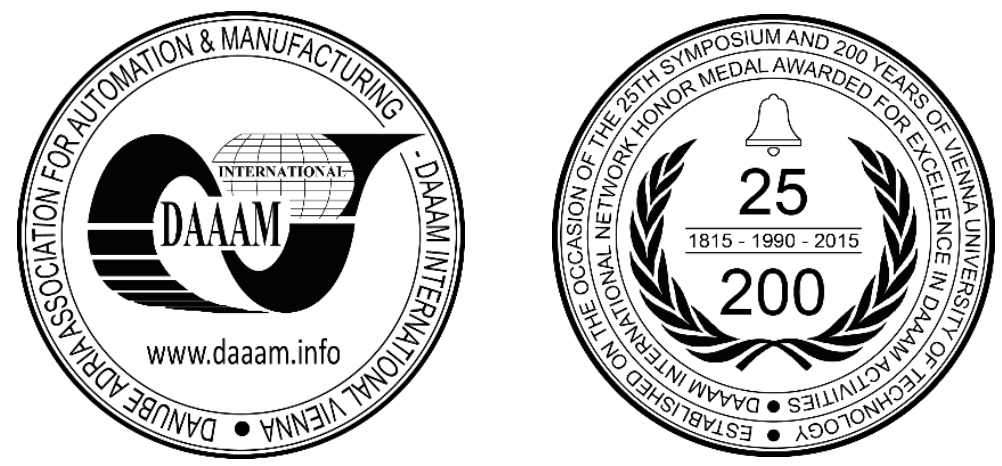

This Publication has to be referred as: Votrubec, R[adek] (2016). Stiffness Control of Orthopaedic Mattress, Proceedings of the 27th DAAAM International Symposium, pp.0230-0234, B. Katalinic (Ed.), Published by DAAAM International, ISBN 978-3-902734-08-2, ISSN 1726-9679, Vienna, Austria

DOI: $10.2507 / 27$ th.daaam.proceedings.034

\begin{abstract}
The paper deals with the stiffness control of enhanced orthopaedic mattress. There are several pneumatic elements into body of the mattress. Pressures in the elements are measured by the pressure sensors. Input and output flows of air are controlled by set of pneumatic valves. All components including compressor are implemented in the bed. First control algorithm was designed in LabVIEW. The final solution is implemented by a microprocessor Arduino. It is possible to set desired stiffness on two zones of mattress, in place of shoulders and in place of hips. The system has two modes. Desired values can be adjusted manually according to achieving equal position of the spine. In the second case, the stiffness can be changed dynamically and may act against bedsore.
\end{abstract}

Keywords: vibroisolation; orthopaedics; sleep quality; Arduino; PUR foam

\section{Introduction}

Getting enough sleep is important for all people, because the body regenerates during it. We spend sleeping approximately one third of our lives. Choice of beds and mattresses is important for the quality of sleep. There is a large amount of mattresses on the market. Some of them are adjustable. Adjustability mostly consists in the possibility to replace inserts with a different hardness. Usually two or three options are only possible, hard-soft or hard-medium-soft. It is described in [1]. The goal was to develop user friendly pneumatic system for fluent control stiffness of mattress in areas of shoulders and hips. It enables to set the correct position of the spine, fig.1
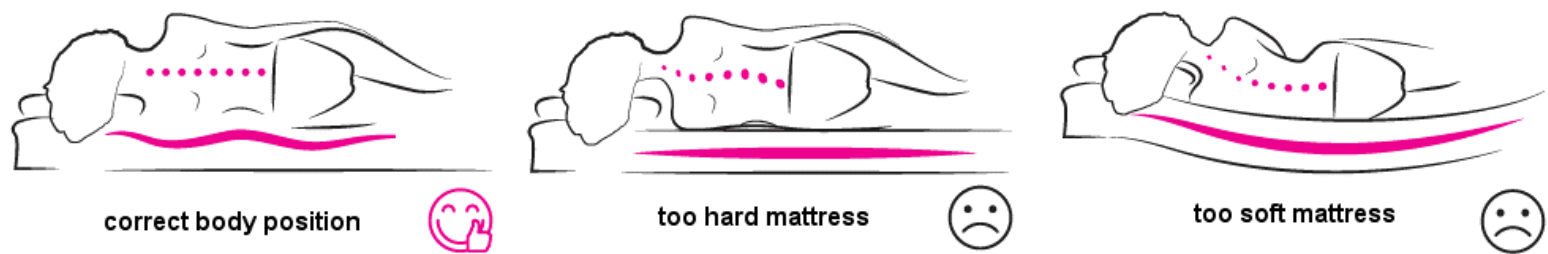

Fig. 1. Correct and wrong body position 
The innovation of mattresses is part of project of computer-aided simulation tools [2]. The most critical factor is the speed of implementation of the particular innovation. High demands on the quality of process control require the use of supporting tools that enable us to get complex and detailed analysis of the process. We have dealt with similar systems in our department at our university. It is especially controlled stiffness of car seat or other pneumatic systems [3, 4]. This topic is related to work on other vibroisolation systems such as active ambulance stretcher [5] or platform stabilized by means of gyroscopes [6].

\section{Description of mattress}

Lamellar orthopaedic mattress was used for our system, fig.2. The basis of the mattress is lamella grid. Three beams made of PUR foam supports the grid. Replaceable inserts with different hardness were replaced by pneumatic elements, fig.3. The force acting from the bottom on the lamella grid depends on the pressure in the pneumatic element. PUR foam is inserted into pneumatic elements. It guarantees minimal force during zero pressure. We have discussed how many zones is optimal. Then we chose two zones only.

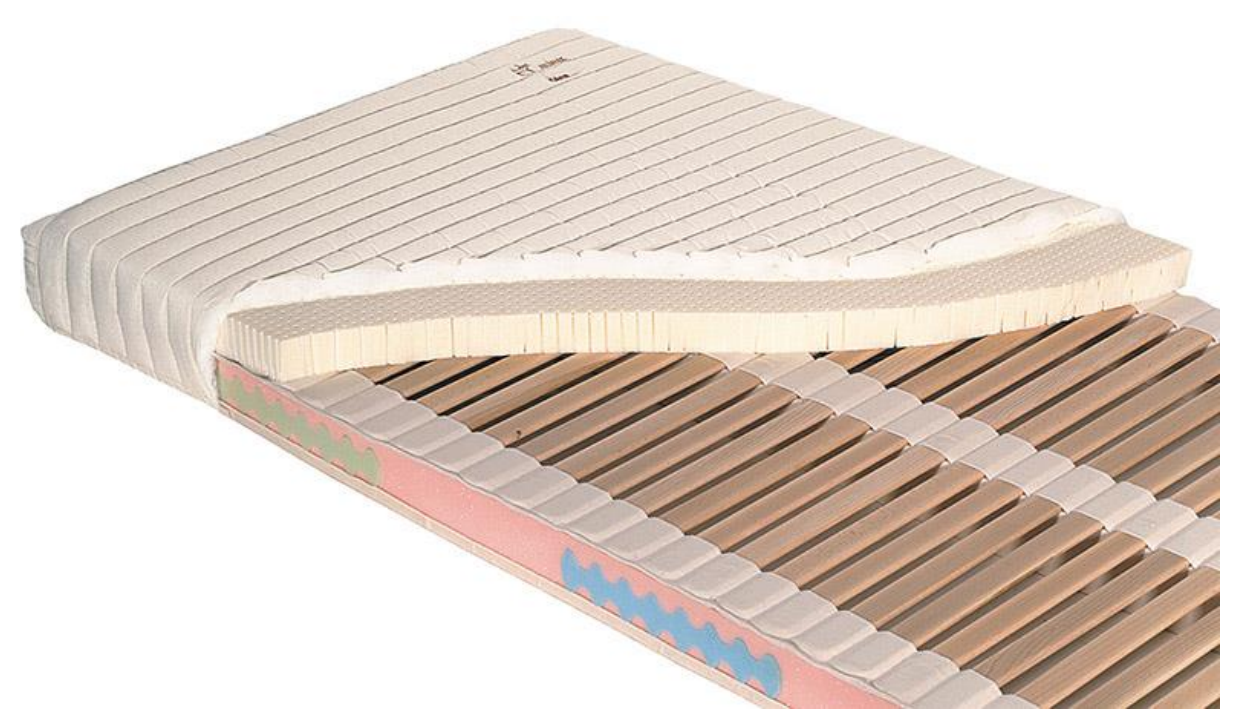

Fig. 2. Lamellar orthopaedic mattress

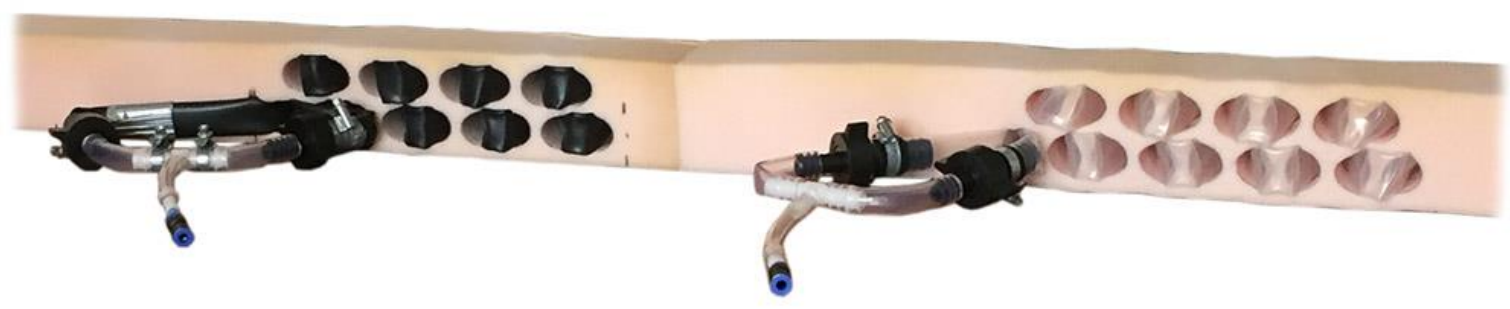

Fig. 3. Pneumatic elements

Articles [7,8] deal with measurement and modelling of damping force of compressed polyurethane foam. Force is described as function of displacement and velocity (1), where coefficients $\alpha$ and $b_{\alpha}$ are difficult to determine.

$$
F_{d}(x, \dot{x})=b_{\alpha} x^{\alpha} \dot{x}
$$

This is a hysteresis curve, which can be identified by measuring. Special tool was constructed for this purpose, fig 4. Measured force in case of various pressures is in fig. 5. Achieved hardness values of mattress with pneumatic elements exceed the range of hardness of standard original mattresses. Interaction between body and parts of some subject is described in [9]. Used methods can be useful for us in the future. 


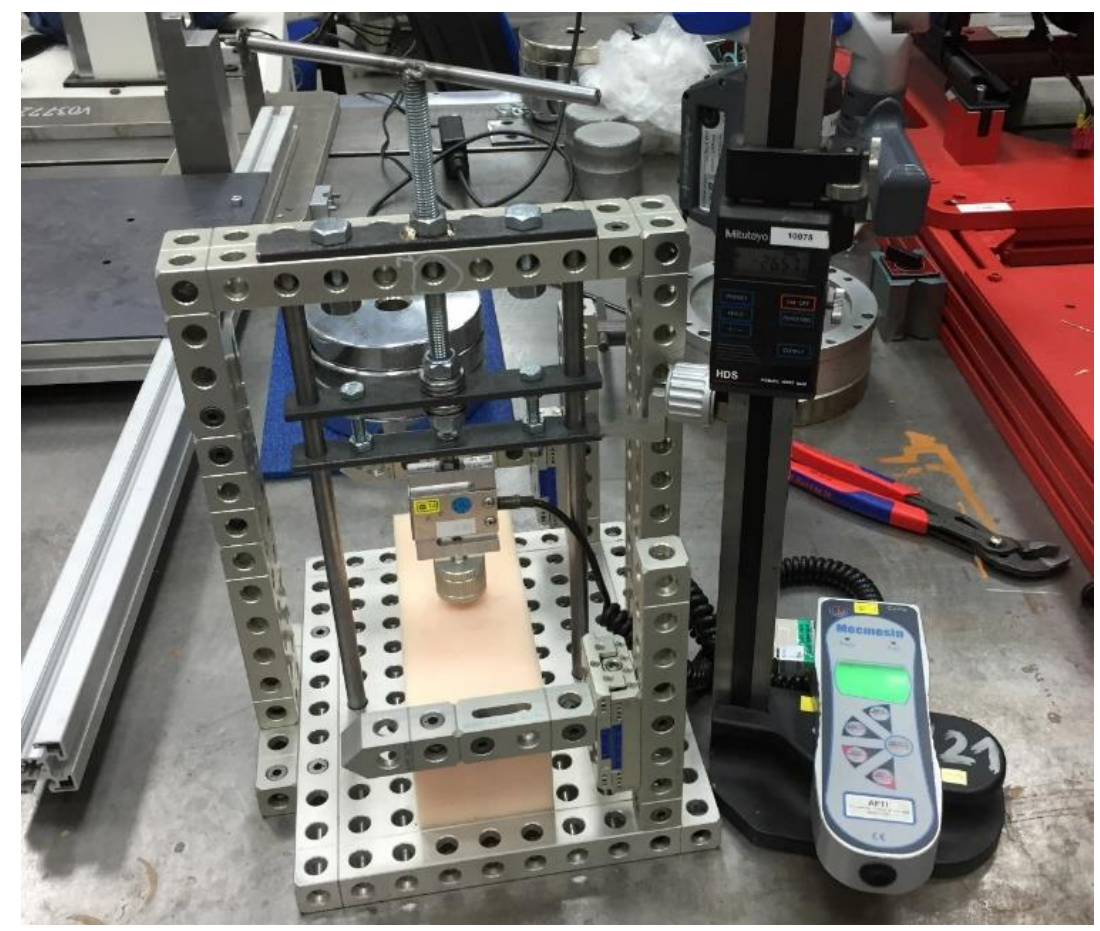

Fig. 4. Tool for measurement of PUR foam force

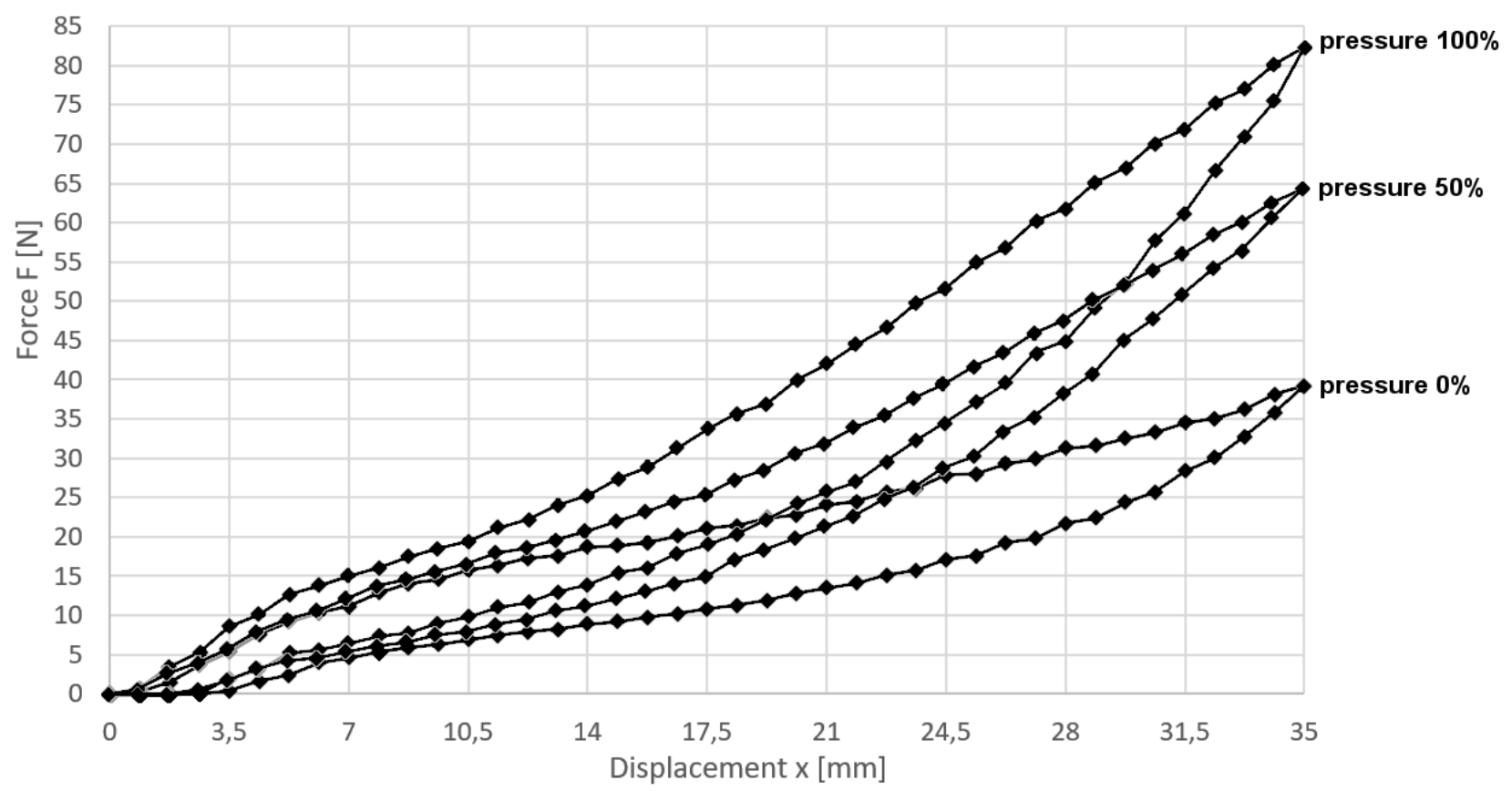

Fig. 5. Measurement of PUR foam force

\section{Electric and pneumatic equipment}

The scheme of control circuit with actuators, sensors and accessories is in fig. 6. Compressor K supplies pressure air to reservoir R. Sensor PK measures pressure in reservoir. Two state on/off control is used to controlling the compressor. Couple of discrete valves is used to control pressure in each zone. Pressures in pneumatic elements are measured with sensors P1 and P2. All components are connected to Arduino. Maximal current of Arduino digital output is 20mA only. We designed contactless relays for digital outputs, fig. 6 on the right side. They consist of optical isolation circuit and power MOSFET transistor. 


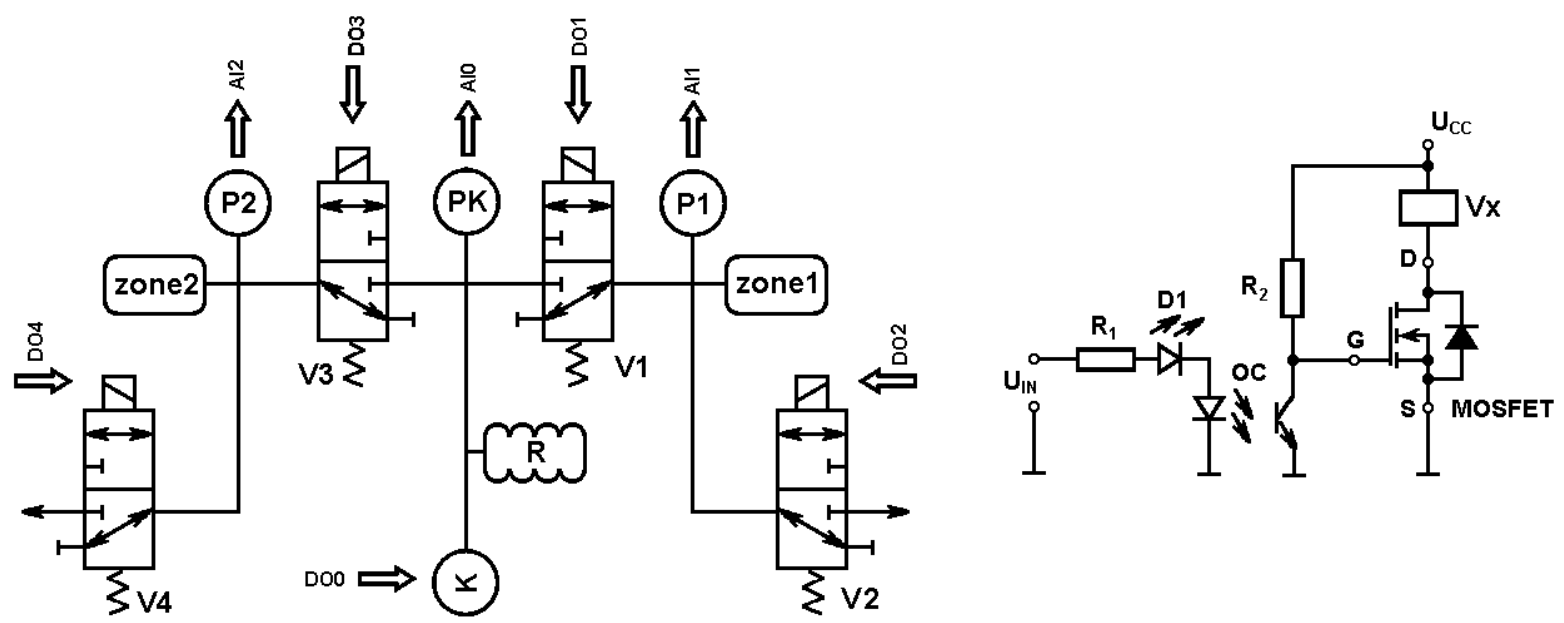

Fig. 6. Pneumatic and electric scheme

The pressure in both zones can be independently adjusted using potentiometers. They are connected to analog inputs of Arduino. Control algorithm is finally realized in Arduino. Proper adjustment pressures in both zones to achieve the correct position of the spine and hips while sleeping, fig. 7. There are two situations in fig.7, wrong position of spine in upper picture and correct position of spine in lower picture. In this case In this case the hip is at right angles to ground.
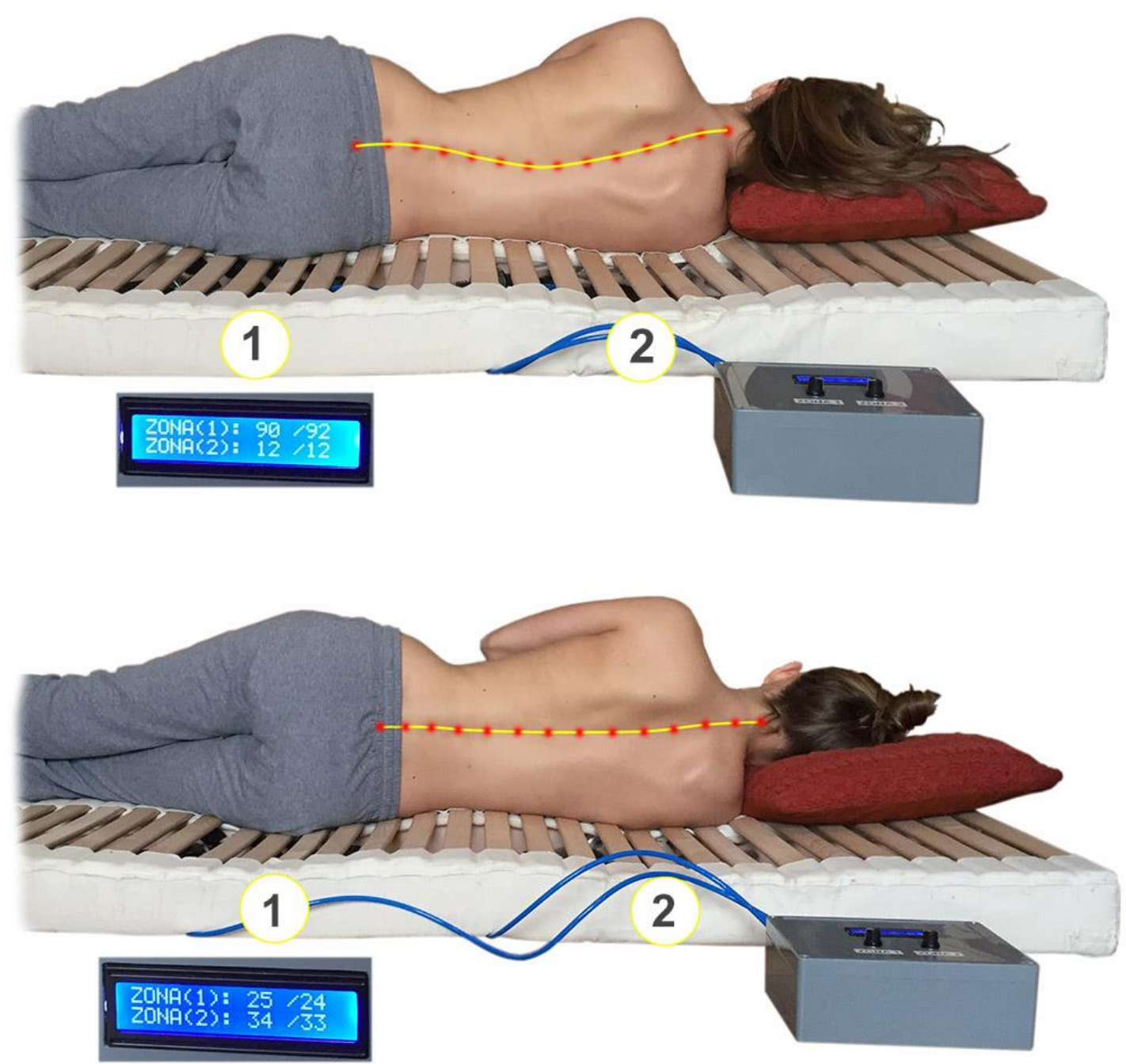

Fig. 7 Wrong and correct position of spine and hips while sleeping 


\section{Conclusion}

The problem was to design user friendly pneumatic system for control stiffness of mattress in areas of shoulders and hips that enables to set the correct position of the spine during sleeping. Five solutions were designed and the best one was selected. The prototype of adjustable orthopaedic mattress with variable stiffness was created. Its control system was designed and realized. Control application with control algorithms was programmed in Arduino. Satisfactory results of control pressure in pneumatic element were obtained. Currently, a group of people testing the mattress. They evaluate the quality of sleep. We are going to offer our solution to furniture manufacturers in Czech Republic. Next it is possible to change standalone microprocessor board instead of Arduino. We are going to find cheaper components suitable for series production. In the future we are going to design some equipment to measure the position of spine. It will enable good setting of pressure in both zones.

\section{Acknowledgments}

The research has been supported by project SGS 21001-115 "Research and development of control structures of pneumatic, hydraulic and electrical components".

\section{References}

[1] http://www.jelinek.eu, (2006). The Furniture Jelinek, Accessed on: 2016-09-30

[2] Manlig, F., Slaichova, E., Koblasa, F., Vavruska, J.. Innovation of Business Processes by Means of Computer-Aided Simulation.Applied Mechanics and Materials. 2014, vol. 474, p. 67-72. DOI: 10.4028/www.scientific.net/ AMM.474.67. ISSN 1660-9336

[3] Votrubec, R. Control system of the seat with variable stiffness. In: Proceedings of the 16th International Conference on Mechatronics - Mechatronika 2014. IEEE, 2014, p. 314-317. ISBN 978-80-214-4816-2

[4] Votrubec, R. \& Vavrousek, M. Control system of a rotary pneumatic motor. In: Proceedings of the 16th International Conference on Mechatronics - Mechatronika 2014. IEEE, 2014, p. 588-593. ISBN 978-80-214-4816-2

[5] Votrubec, R. Control of active sanitary coach, In: Annals of DAAAM for 2011 \& Proceedings of the 22th International DAAAM Symposium, s. 617-618, DAAAM,International, Vienna, Austria, 2011, ISSN: 1726-9679, ISBN: 9783901509834

[6] Votrubec, R. Stabilization of platform using gyroscopes, In: Annals of DAAAM for 2013 \& Proceedings of the 24rd International DAAAM Symposium "Intelligent Manufacturing \& Automation", Editor B.[ranko] Katalinic, ISSN 1877-7058, 23-26th October 2013, Zadar, Croatia

[7] Cirkl,D. Modelling of damping force of dynamically loaded specimen of polyurethane foam in dependence on its density. Shock and Vibration 17 (2010), ISSN: 1070-9622, 373-381

[8] Jiga, G, Stamin, S., Dinu, G., Dobrescu, T, Popovici, D. Comparative Studies on the Impact Behavior of Two Sandwich Structures. Procedia Engineering [online]. 2015, 100, 418-427 [cit. 2016-10-03]. DOI: 10.1016/j.proeng.2015.01.386. ISSN 18777058

[9] Harih G., Borovinsek M., Ren Z., Dolsak B. (2015). Optimal Products' Hand-Handle Interface Parameter Identification. Int. Journal of Simulation Modelling, Vol. 14, No. 3, p. 404-415 